\title{
Modeling the Impact of Airport Deicing and Anti-icing Activities on Dissolved Oxygen Levels in the Receiving \\ Waterways
}

\author{
Bancha Ariyajunya, ${ }^{1}$ Prashant K. Tarun, ${ }^{2}$ Victoria C. P. Chen ${ }^{1}$ and Seoung Bum Kim ${ }^{3}$ \\ ${ }^{1}$ University of Texas at Arlington, Arlington, Texas; ${ }^{2}$ Missouri Western State University, Saint Joseph, Missouri; ${ }^{3}$ Korea University, Sungbuk-gu, \\ Seoul, Korea.
}

\begin{abstract}
This paper evaluates the efficacy of the environmental management system (EMS) at Dallas Fort Worth International Airport (DFW) in capturing spent aircraft deicing fluids to prevent their discharge into receiving waterways. DFW claims that its EMS captures the spent aircraft deicing fluids completely, leaving only the spent aircraft anti-icing fluids to contribute to drip and shear during taxiing and takeoff and subsequent runoff to the waterways. Glycols in the aircraft deicing and anti-icing fluids reduce dissolved oxygen (DO) in the airport's receiving waterways upon mixing with it during aircraft deicing operations.
\end{abstract}

To evaluate the airport's EMS claim, two decision tree models were built: one with anti-icing glycol usage as a predictor variable, and one with separated deicing glycol usage and anti-icing glycol usage as predictor variables. The analyses suggest that deicing glycol usage is more significant for predicting DO concentrations in the airport's receiving waters than is anti-icing glycol usage.

\section{Introduction}

Airplane deicing and anti-icing activities are carried out at airports worldwide during harsh winter conditions to ensure aircraft safety, thereby ensuring safer transportation of people, materials, and goods across the globe (Bruno et al. 2015; Revitt and Worrall 2003; Revitt et al. 2001; Switzenbaum et al. 1999; Leist et al. 1997; FAA Report 1996). Deicing is performed to remove ice after it begins to form on the airplane whereas anti-icing is performed to prevent ice formation. Airplane deicing and anti-icing activities typically involve the use of deicing and anti-icing fluids (ADAF). Deicing fluids typically contain proportions of ethylene glycol, propylene glycol and diethylene glycol as well as water, corrosion inhibitors, wetting agents, dye, and proprietary additives (Commercial and Business Aviation Training Manual 2004; FAA Maintenance Handbook Series 2012). Anti-icing fluids have chemical formulations similar to deicing fluids except that they also contain polymeric thickeners. Anti-icing fluids are more viscous and have higher percentages of additives than deicing fluids (Commercial and Business Aviation Training Manual 2004; Corsi et al. 2006). ADAF runoff into the airport's receiving waters can cause a decrease in dissolved oxygen (DO) and an increase in the toxicity of the water (Corsi et al. 2006; Masters 1997; U.S. Environmental Protection Agency 2000).

Our study focuses on the deicing and anti-icing activities at Dallas Fort Worth International Airport (DFW). Typically, DFW experiences meteorological conditions that require airplanes to undergo deicing or anti-icing operations in accordance with Federal Aviation Administration (FAA) safety regulations from late October to early April. In the aftermath of a devastating fish kill in 1999 in Trigg Lake (a local reservoir for ADAF runoff) caused by the deicing-anti-icing activities at the airport, DFW upgraded its ADAF collection systems to comply with water quality regulations and to meet the FAA safety regulations regarding deicing-anti-icing operations (Corsi et al. 2006). ADAF runoff is now collected at eight deicing pads, and then pumped out to the airport's reverse osmosis wastewater treatment system.

According to DFW, the airport's environmental management system captures the spent aircraft deicing fluids completely $(100 \%)$, so preventing their discharge into the creeks and rivers surrounding the airport (U.S. Environmental Protection Agency 2000). Consequently, only spent aircraft anti-icing fluids contribute to drip and shear and subsequent runoff to the airport's receiving waters; some amount of fluid drips from the airplane before takeoff, and the remaining fluid shears from the airplane during takeoff (Corsi et al. 2006). As stated, ADAF runoff into the airport's receiving waters can have an adverse impact on the ecology of receiving waterways because of reduced DO concentrations (Corsi et al. 2006; U.S. Environmental Protection Agency 2000; Masters 1997). To keep track of DO concentrations in airport receiving waterways during deicing-anti-icing periods, DFW partnered with the U. S. Geological Survey (USGS) to set

Ariyajunya, Bancha, Prashant K. Tarun, Victoria C. P. Chen and Seoung Bum Kim. 2018. Modeling the Impact of Airport Deicing and Anti-icing Activities on Dissolved Oxygen Levels in the Receiving Waterways. Journal of Water Management Modeling 26:C441. https://doi.org/10.14796/JWMM.C441 () CHI 2018. www.chijournal.org ISSN 2292-6062. 
up a system for collecting water quality data at nine sites in the airport's receiving waterways: an urban reference site at Blessing Branch (BLSN); an upstream reference site on Big Bear Creek at Euless/Grapevine road near Grapevine, Texas (REF); an airport drainage site at Outfall 19 on an unnamed tributary to Big Bear Creek near Euless, Texas (OF19); an airport site draining into Trigg Lake (IN); three sites within Trigg Lake (S1, S2 and S3); a Trigg Lake outflow site (OUT); and a downstream site on Big Bear Creek at SH 183 near Euless, Texas (DNST). BLSN and REF are reference sites because they are not affected by airport activities. DO concentrations at sites S1, S2 and S3 within Trigg Lake and sites OUT and DNST downstream of Trigg Lake are impacted by aerators in Trigg Lake. Sites IN and OF19 continue to be affected by airport activities. Figure 1 shows the layout of the nine USGS monitoring sites (squares) and eight deicing pad locations (circles) at DFW.

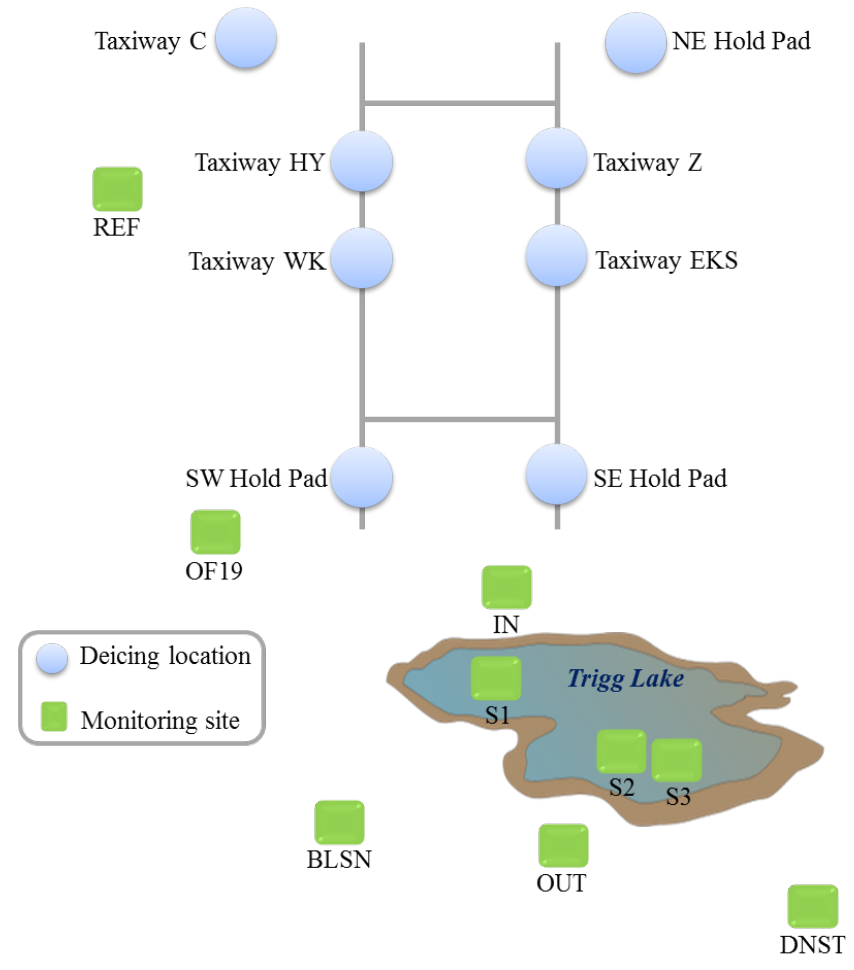

Figure 1 Schematic diagram of USGS monitoring sites (squares) and deicing pad locations (circles) at DFW.

DFW utilizes these data to monitor DO concentrations in its receiving waters for the purpose of improving its deicinganti-icing practices. In this study, we set out to examine DFW's hypothesis that the deicing fluids are completely captured before planes exit the deicing pad, leaving only the anti-icing fluids to runoff into the airport's receiving waters from drip and shear. We use decision trees to examine this hypothesis regarding the efficacy of DFW's ADAF collection facilities, using some of the results from Kim et al. (2007) and Fan et al. (2011).

\section{Materials and Methods}

\subsection{Data}

The following data sets were merged for this study. The first data set was collected by DFW in collaboration with USGS. The second data set was collected by DFW, and the third one was modified for analysis. They are:

1. USGS continuous monitoring at nine sites: DO, discharge, water temperature, precipitation, and stage were monitored at the following sites shown in Figure 1: BLSN, REF, DNST, OF19, IN, OUT, S1, S2, and S3.

2. Airport deicing activities: Ethylene glycol usage, propylene glycol usage, and deicing pad usage at eight deicing pad locations were recorded; deicing pad locations and time durations are shown in Table 1.

3. Airport meteorology: Hourly air temperature, hourly precipitation, hourly dew point temperature, hourly wind speed and direction were taken from TDL U.S. and Canada Surface Hourly Observations (http://rda. ucar.edu/datasets/ds472.0/) for the DFW stations located in the area bounded by latitudes $32.5^{\circ} \mathrm{N}$ to $33.5^{\circ} \mathrm{N}$ and longitudes $96.5^{\circ} \mathrm{W}$ to $97.5^{\circ} \mathrm{W}$ for the period 2002-2004.

Table 1 Deicing pad locations and time durations (Fan et al. 2011).

\begin{tabular}{lll}
\hline \multicolumn{1}{c}{ Pad Locations } & \multicolumn{1}{c}{ Duration } \\
\hline Taxiway EKS & $10 / 27 / 2002-04 / 09 / 2003 ; 11 / 07 / 2003-03 / 12 / 2004$ \\
Taxiway WK & $11 / 05 / 2002-04 / 09 / 2003 ; 12 / 11 / 2003-02 / 27 / 2004$ \\
Taxiway HY & $11 / 28 / 2002-04 / 09 / 2003 ; 11 / 09 / 2003-02 / 26 / 2004$ \\
Taxiway Z & $11 / 28 / 2002-02 / 26 / 2003 ; 12 / 14 / 2003-02 / 15 / 2004$ \\
Taxiway C & $10 / 24 / 2002-02 / 28 / 2003 ; 12 / 01 / 2003-03 / 29 / 2004$ \\
Hold pad SE & $11 / 28 / 2002-03 / 25 / 2003 ; 12 / 08 / 2003-02 / 26 / 2004$ \\
Hold pad SW & $12 / 24 / 2002-02 / 27 / 2003 ; 12 / 24 / 2003-02 / 26 / 2004$ \\
Hold pad NE & $01 / 12 / 2003-02 / 26 / 2003 ; 02 / 14 / 2004$ \\
\hline
\end{tabular}

The USGS continuous monitoring data were obtained via sensors every $15 \mathrm{~min}$ to $20 \mathrm{~min}$. Glycol usage for each day was aggregated by airline and deicing pad location. The data for meteorological variables were collected hourly. The following data sets were created to facilitate the analyses presented here:

1. Data set 1: hourly-averaged USGS continuous monitoring data for the nine sites;

2. Data set 2: merged data set consisting of DO data from USGS continuous sampling, airport deicing activities, and airport meteorology for days on which deicing-anti-icing activities occurred during the 2002-2003 and 2003-2004 deicing seasons;

3. Data set 4 (airport deicing activities): number of airplanes, ethylene and propylene glycol usage, deicing 
pad usage at taxiways EKS, WK, HY, Z and $\mathrm{C}$ and hold pads SE, SW and NE; and

4. Data set 5 (airport meteorology): hourly data for air temperature, precipitation, dew point, wind speed and wind direction.

Since deicing activities were only recorded by day for data set 2 , measurements taken $>1$ time/d were aggregated to obtain a daily measure. The daily minimums of hourly-averaged DO were obtained and the daily averages were calculated for other variables, with the exception of daily precipitation which was obtained by adding hourly precipitation measures over the day. Wind speed and wind direction variables in the meteorological data were transformed using the method described by Fan et al. (2011).

\subsection{Decision Tree Methodology}

Decision tree methodology, conceptualized by Breiman et al. (1984), is used to analyze the effects of deicing and anti-icing activities on DO concentrations in the DFW receiving waters. The merits of decision tree methodology are discussed in the works of Tsui et al. (2006), Huo et al. (2006), Hand et al. (2001), Mistikoglu et al. (2015) and Mantas and Abellan (2014). Decision trees are adept at handling both continuous and categorical variables.

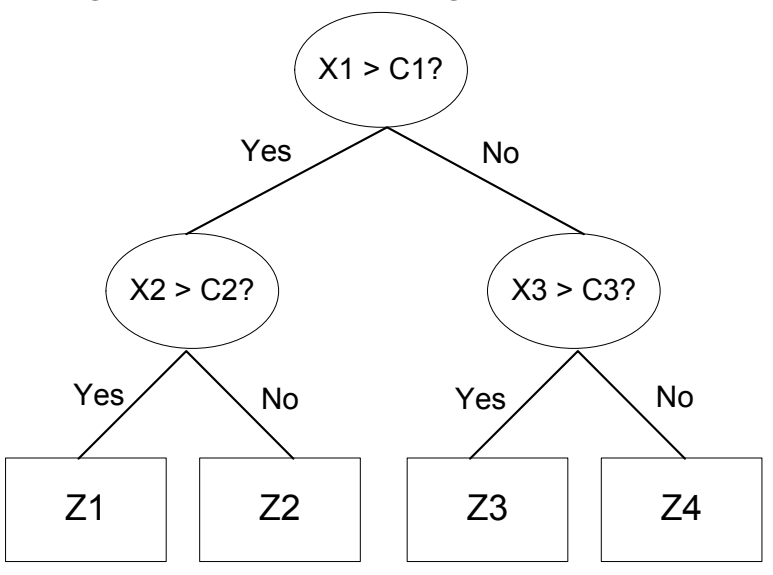

Figure 2 Example of the regression tree model; oval nodes are the intermediate nodes and rectangles are terminal nodes; $\mathrm{C} 1, \mathrm{C} 2$ and $\mathrm{C} 3$ are the splitting values of the variables $X 1, X 2$ and $X 3 ; \mathrm{Z1}, \mathrm{Z} 2, \mathrm{Z} 3$ and $\mathrm{Z} 4$ are the average (or median) values of the response variables in the terminal nodes.

In particular, the regression tree models have been used in our study to see if deicing and anti-icing activities had any effect on DO levels in the DFW receiving waters. The output from the regression tree consists of a set of if-then logical splits for predicting the response variable, an illustration of which is shown in Figure 2 and is described fully in Fan et al. (2011). Least absolute deviation (LAD) is used as the splitting criterion for the regression trees. A comprehensive review of $L A D$ regression methods is given in Narula and Wellington (1982). LAD regression trees use the median and attempt to minimize the mean absolute deviation (Breiman et al. 1984). LAD regression tree models are more robust to the presence of outliers and skewed distributions than least squares regression tree models (Torgo 1999). The testing method we used was 10 -fold cross validation, which involves division of the training data randomly into 10 equal parts. The regression tree models are fit to 9 parts of the division, and the prediction error is calculated on the remaining 1 part. This process is repeated so that for each of the 10 parts in turn a prediction error is calculated, and the ten prediction error estimates are averaged (Hastie et al. 2009). The cross validation method is preferable for smaller sample sizes (Breiman et al.1984).

\section{Analyses and Results}

In order to evaluate the DFW claim that the deicing fluids are completely washed away before the airplanes depart from the deicing pad locations, the decision tree analyses were conducted. The analyses also incorporated DO related results from Kim et al. (2007) and Fan et al. (2011). Two new decision tree models were constructed by first separating the deicing glycol usage (DG) and anti-icing glycol usage (AG) from the total glycol usage (TG) in data set 4 and then adding these variables back into data set 4 . A decision tree model was run with only $A G$ and another decision tree model was run with both DG and AG separated, instead of TG. Next, the relationship between DO in data set 1 and other explanatory variables, including glycol usage (TG, DG and AG) in data set 4 and meteorological variables in data set 5 were examined. As discussed earlier, DO observations were aggregated for a day by first taking hourly averages and then identifying the minimum hourly-averaged DO for that day. Another data set that contained the deicing activities data specific to the particular location was created for each deicing pad location. Glycol usages that were lagged by a day were added subsequently as potential explanatory variables. Table 1 shows deicing pad locations and time durations.

The decision tree analyses were conducted using the software Classification and Regression Trees (CART) (www.salfordsystems.com). CART assigns variable importance scores to help with the variable selection. The variable with an importance score of 100 is deemed the most influential for prediction, followed by other variables in descending order of their importance scores. Variable importance was first defined in Breiman et al. (1984) using a measure $M\left(x_{n}\right)$ involving surrogate split on a variable $x_{n}$. The measure of importance used is the normalized quantity $100 \cdot M\left(x_{n}\right) / \max M\left(x_{n}\right)$, resulting in a value in the range 0 (least important) to 100 (most important).

The first of the two additional decision tree models was built for each deicing pad location by adding only AG instead of TG at monitoring sites IN and OF19, including wind component meteorological variables for north-south wind (NS) and eastwest wind (EW). The second decision tree model was similarly constructed, except for the use of both DG and AG variables separately instead of TG. These two decision tree models are 
compared not only with each other but also with the previous decision tree model based on TG. The summaries of variable importance for the decision tree models at each deicing pad location with TG, with only AG, and both separated DG and AG are shown in Tables 2 through 4 below, respectively.

Our primary focus was to investigate the following associations at the eight deicing pad locations (taxiways EKS, WK, HY, $Z$ and $C$; and hold pads SE, SW and NE): between DO and TG; between DO and AG; and between DO and (DG and AG). Taxiway $Z$ does not appear in Tables 2 through 4 below because deicing and anti-icing activities are not impactful enough at taxiway $Z$ to yield optimal decision trees. A greater insight into these relationships will help DFW to achieve better monitoring and control of the deicing activities at the airport with the sole purpose of minimizing the adverse effects of deicing activities on the quality of the airport receiving waters. Our analyses focus on monitoring sites IN and OF19, since these two sites are affected significantly by deicing activities at the airport (Kim et al. 2007; Fan et al. 2011).

Table 2 shows the rankings of important variables for predicting DO at each deicing pad location in a decision tree model that includes TG and TG Lag (total glycol usage lagged by $1 \mathrm{~d}$ ) as variables. The splitting information associated with Table 2 is shown in tree structures labelled (a) in Figures 3 through 9 below. These results were previously included in Fan et al. (2011), and indicate that TG and TG Lag variables appear in the tree models for taxiways WK and C and hold pad SE. The predictor variables were the monitoring sites (OF19 and IN), TG, TG Lag, and the meteorological variables EW and NS. The key results include the following:

- a high level of TG corresponds with a decrease in DO at monitoring site IN, and a moderately higher TG at taxiway $\mathrm{C}$ corresponds with an increase in DO at monitoring site OF19; and

- a stronger NS wind component contributes to lower DO, while a low EW wind component may contribute to lower DO.

Table 2 Total glycol model including both deicing and anti-icing glycol ( $\mathrm{TG}=$ total glycol usage; TG Lag = total glycol usage lagged by $1 \mathrm{~d}$; EW = east-west wind component; NS = north-south wind component).

\begin{tabular}{lccccc}
\hline \multicolumn{1}{c}{ Ranking } & 1 & 2 & 3 & 4 & 5 \\
\hline Taxiway EKS & Site & & & & \\
Taxiway WK & Site & TG Lag & EW & NS & TG \\
Taxiway HY & NS & Site & EW & & \\
Taxiway C & TG & Site & TG Lag & EW & NS \\
Hold pad SE & EW & NS & Site & TG Lag & TG \\
Hold pad SW & NS & EW & Site & TG & \\
Hold pad NE & Site & & & & \\
\hline
\end{tabular}

The decision trees for taxiways WK, C, and hold pad SE include at least one group with median $\mathrm{DO}<4.0 \mathrm{mg} / \mathrm{L}$, and these low DO groups are associated with high TG.
Table 3 shows the rankings of important variables for predicting DO at each deicing pad location in a decision tree model that includes the AG variable. The splitting information associated with Table 3 is shown in tree structures labelled (b) in Figures 3 through 9 below. The predictor variables were for monitoring sites (OF19 and IN), AG, and the meteorological variables EW and NS. No optimal trees were obtained for taxiway $C$ or hold pads SE, SW and NE. Furthermore, the tree models for taxiways EKS, WK and HY are weaker as they do not show AG to be an important variable.

Table 3 Only anti-icing glycol usage (AG) model (no tree when the data size was too small).

\begin{tabular}{lccc}
\hline \multicolumn{1}{c}{ Ranking } & 1 & 2 & 3 \\
\hline Taxiway EKS & Site & & \\
Taxiway WK & Site & NS & NS \\
Taxiway HY & EW & AG & \\
Taxiway C & No tree & & \\
Hold pad SE & No tree & & \\
Hold pad SW & No tree & & \\
Hold pad NE & No tree & & \\
\hline
\end{tabular}

Table 4 shows the rankings of important variables for predicting DO at each deicing pad location in a decision tree model that includes separate DG and AG variables. The splitting information associated with Table 4 is shown in tree structures labelled (c) in Figures 3 through 9 below. The predictor variables were for the monitoring sites (OF19 and IN), DG, AG, DG Lag (DG lagged by 1 d), AG Lag and the meteorological variables EW and NS. The key results include the following:

- AG Lag appears in the decision tree model for taxiway WK, as shown in Figure 6(c) below;

- DG appears in the decision tree model for taxiway C, as shown in Figure 7(c) below; a higher value of DG at taxiway $C$ corresponds with a lower DO concentration at monitoring site IN; a moderate value of DG at taxiway $C$ corresponds to a higher DO concentration at monitoring site OF19; and

- DG Lag appears in the decision tree model for SW hold pad, as shown in Figure 9 (c) below; a higher value of DG Lag at SW hold pad corresponds with a lower DO concentration at monitoring site IN.

Table 4 Separated deicing and anti-icing glycol model (AG Lag = anti-icing glycol lagged by $1 \mathrm{~d}$; DG Lag = deicing glycol lagged by $1 \mathrm{~d}$ ).

\begin{tabular}{lccccccc}
\hline \multicolumn{1}{c}{ Ranking } & 1 & 2 & 3 & 4 & 5 & 6 & 7 \\
\hline Taxiway EKS & Site & & & & & & \\
Taxiway WK & Site & AG Lag & DG Lag & EW & NS & AG & DG \\
Taxiway HY & Site & NS & DG Lag & AG Lag & AG & EW & \\
Taxiway C & DG & Site & DG Lag & AG Lag & EW & NS & AG \\
Hold pad SE & Site & & & & & & \\
Hold pad SW & NS & DG Lag & EW & Site & AG Lag & DG & \\
Hold pad NE & Site & & & & & & \\
\hline
\end{tabular}



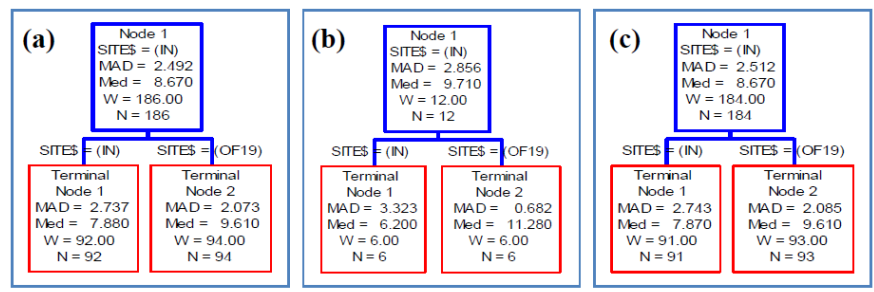

Figure 3 Taxiway EKS tree structures: (a) total glycol; (b) only anti-icing; (c) deicing and anti-icing.
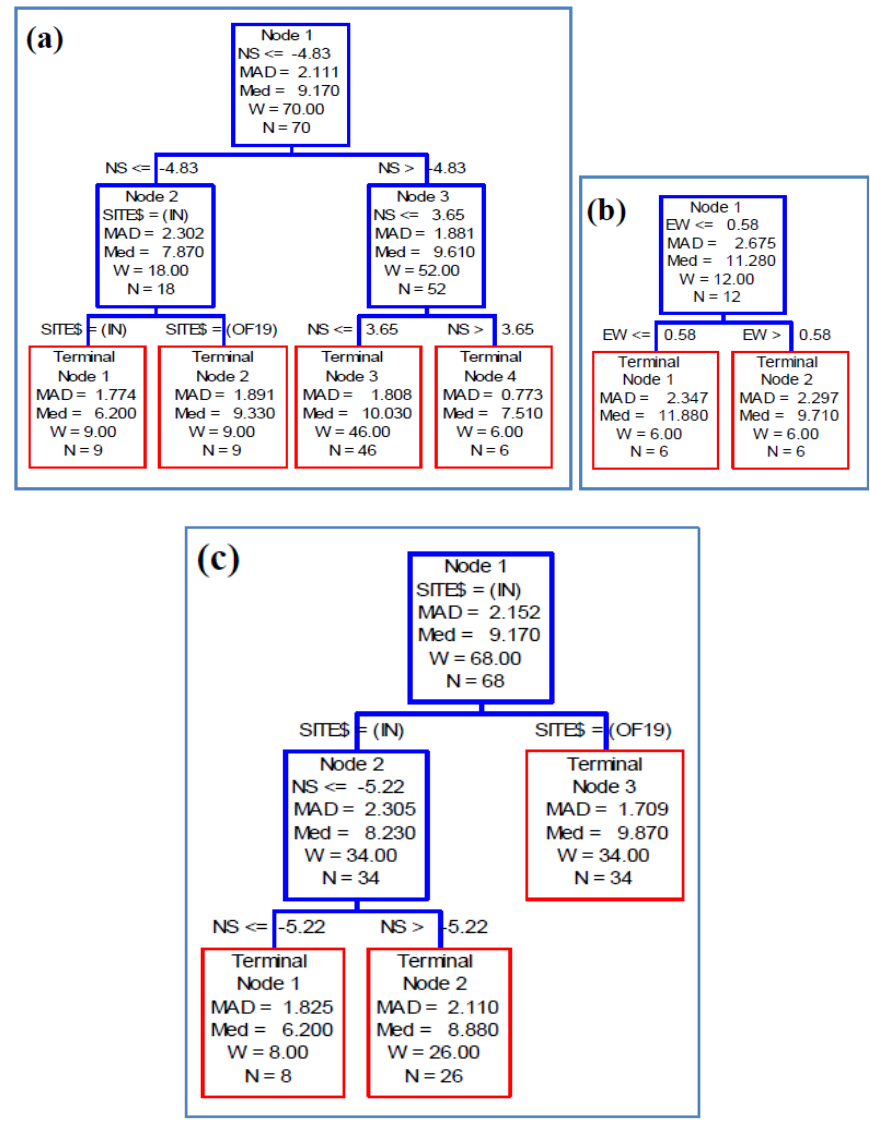

Figure 4 Taxiway HY tree structures: (a) total glycol; (b) only anti-icing; (c) deicing and anti-icing.
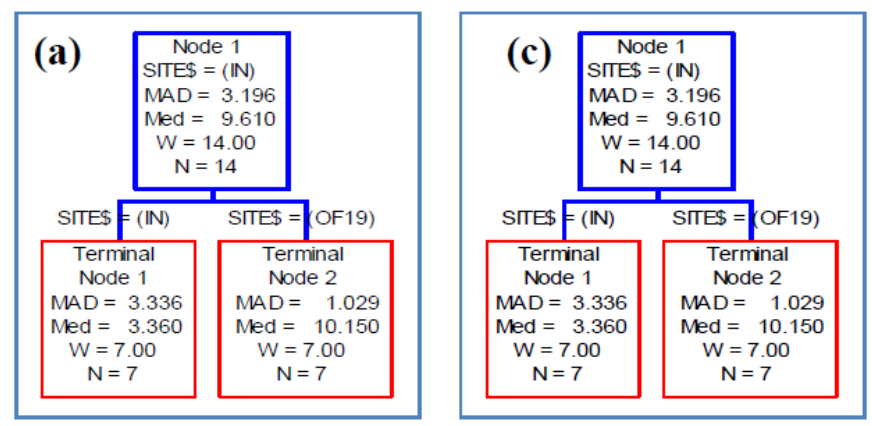

Figure 5 Hold pad NE tree structures: (a) total glycol; (c) deicing and anti-icing (no tree for only anti-icing).
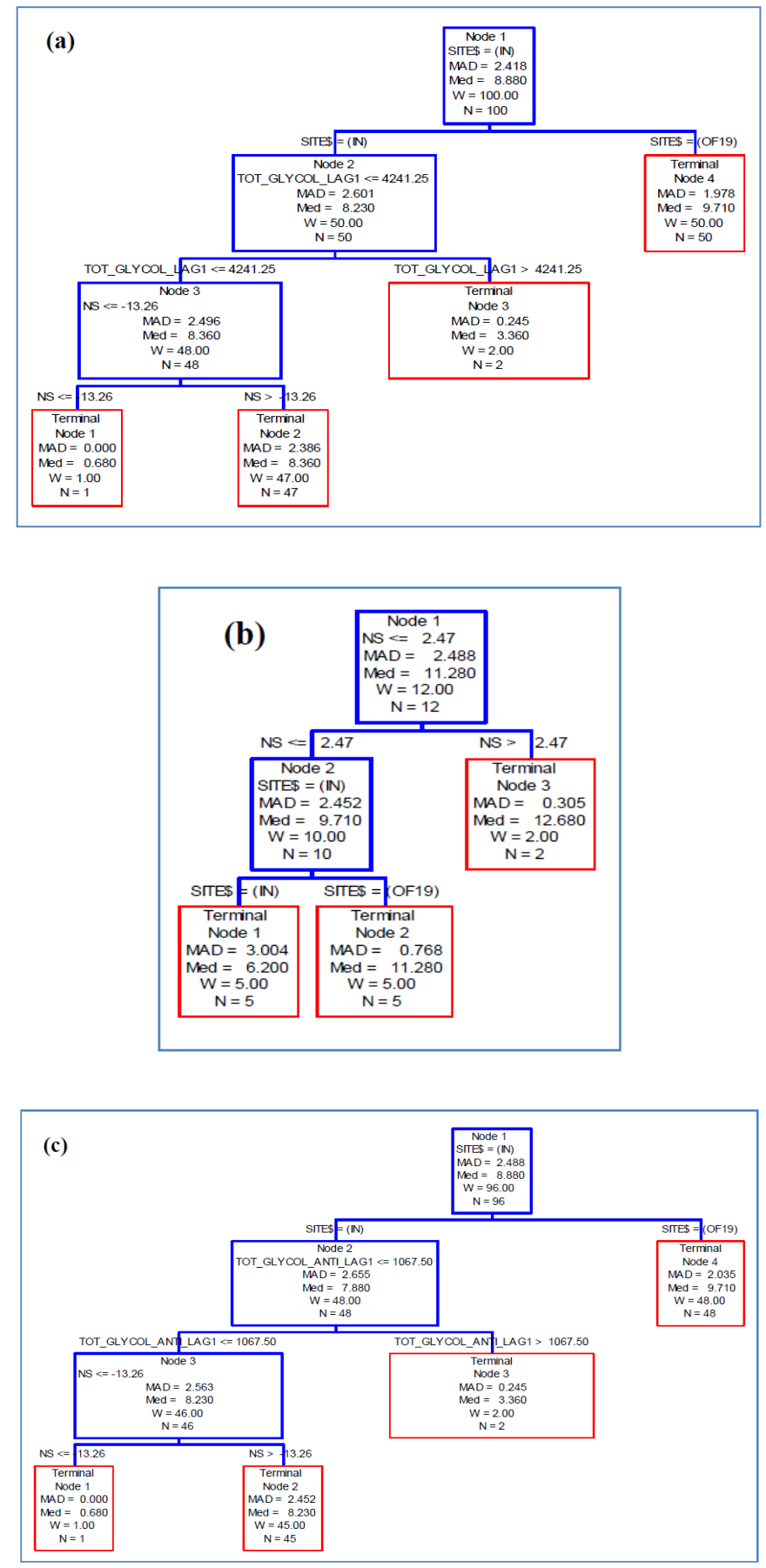

Figure 6 Taxiway WK tree structures: (a) total glycol; (b) only anti-icing; (c) deicing and anti-icing. 

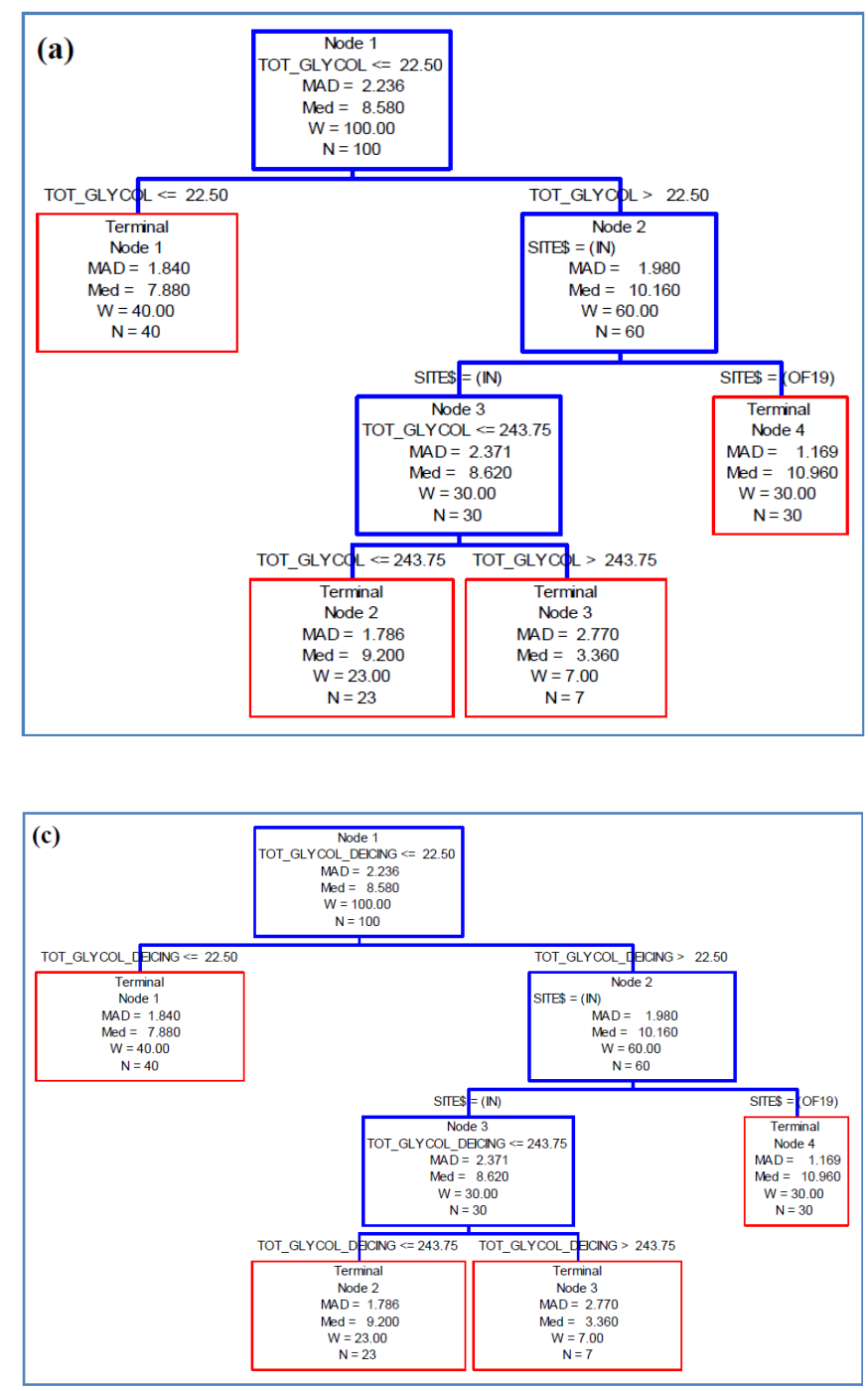

Figure 7 Taxiway C tree structures: (a) total glycol; (c) deicing and anti-icing (no tree for only anti-icing).

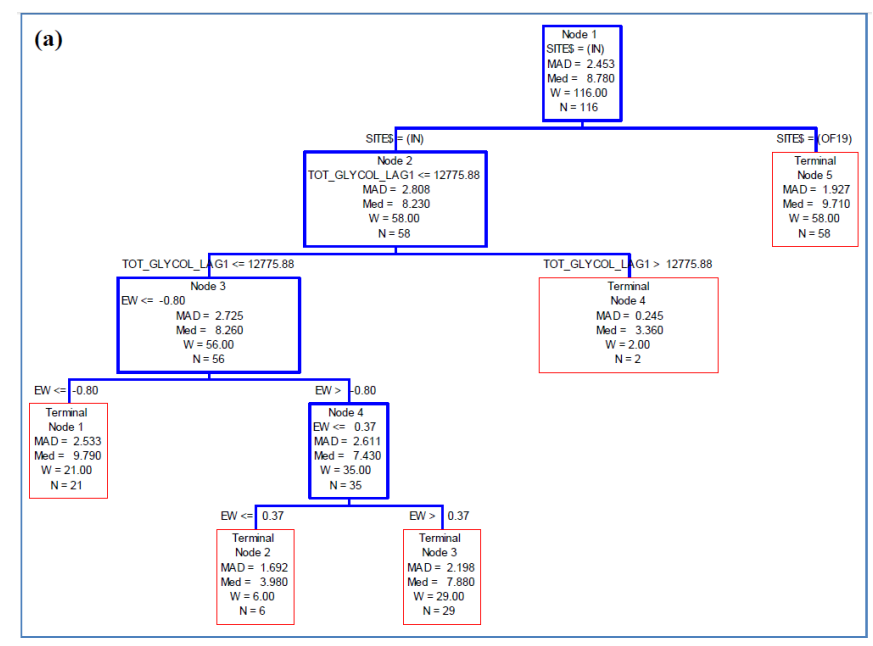

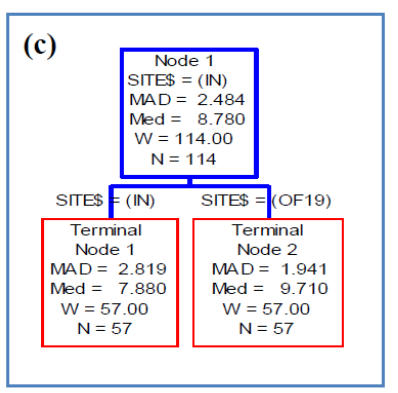

Figure 8 Hold pad SE tree structures: (a) total glycol, (c) deicing and anti-icing (no tree for only anti-icing).
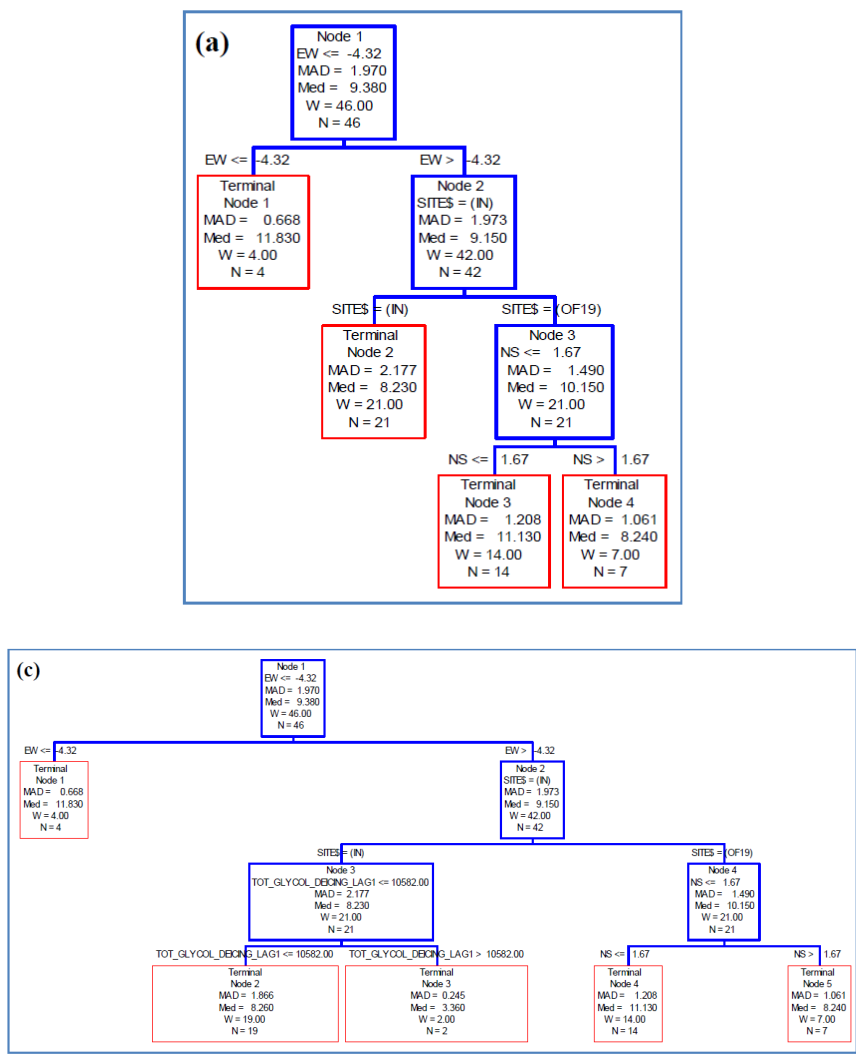

Figure 9 Hold pad SW tree structures: (a) total glycol; (c) deicing and anti-icing (no tree for only anti-icing).

Tables 5 through 7 show various groups of DO observations in the decision trees for taxiways WK and $C$ and for hold pad SW. In Table 5 for taxiway WK, there are only 3 observations ( 1 observation in group 1 and 2 observations in group 3 ) at monitoring site IN with a relatively lower median DO ( $<4.0 \mathrm{mg} / \mathrm{L}$ ). A very low median DO of $0.68 \mathrm{mg} / \mathrm{L}$ corresponds to a single measurement at monitoring site IN with AG Lag $\leq 1067.50 \mathrm{mg} / \mathrm{L}$. In Table 6 for taxiway C, there are 7 observations in group 3 at monitoring site IN with a relatively lower median DO (<4.0 mg/L). In Table 6 for hold pad SW, there are only 2 observations in group 3 at monitoring site IN with a relatively 
lower median DO ( $<4.0 \mathrm{mg} / \mathrm{L})$. For taxiway $\mathrm{C}$ and hold pad SW, group 3 with low median DO is associated with high DG. It is important to note that the low median DO observations occur at monitoring site IN, which is significantly impacted by the deicing and anti-icing activities at DFW. These groups with low median DO contain fewer observations, but require attention from DFW. These are precisely the situations that DFW needs to avoid in order to mitigate the effects of their deicing practices. To that end, aerators installed by DFW in Trigg Lake are automatically triggered when the DO concentration in the lake drops to $\leq 7 \mathrm{mg} / \mathrm{L}$. A study of the impact of aerators in Trigg Lake can be found in Kim et al. (2007). According to Kim et al. (2007), when DO concentration at monitoring site IN was $\leq 7 \mathrm{mg} / \mathrm{L}$, the mean DO concentration at monitoring site OUT was significantly higher than the mean DO at monitoring site IN during the 20022003 and 2003-2004 deicing seasons. DFW can also benefit from an optimization-simulation tool proposed in the study by Fan et al. (2017) that helps to evaluate actual operational scenarios at the airport under various conditions in order to find ways to improve the ecological impact of the current deicing practices at the airport.

Table 5 Groupings of DO observations in taxiway WK for the separated deicing and anti-icing glycol decision tree model.

\begin{tabular}{lcccc}
\hline \multicolumn{1}{c}{ Group } & 1 & 2 & 3 & 4 \\
\hline Site & IN & IN & IN & OF19 \\
WK AG Lag (mg/L) & $\leq 1067.50$ & $\leq 1067.50$ & $>1067.50$ & \\
NS (mi/h) & $\leq-13.26$ & $>-13.26$ & & \\
Median D0 (mg/L) & 0.68 & 8.23 & 3.36 & 9.71 \\
\# Observations & 1 & 45 & 2 & 48 \\
\hline
\end{tabular}

Table 6 Groupings of DO observations in taxiway $\mathrm{C}$ for the separated deicing and anti-icing glycol decision tree model.

\begin{tabular}{lcccc}
\hline \multicolumn{1}{c}{ Group } & 1 & 2 & 3 & 4 \\
\hline Site & & IN & IN & OF19 \\
Taxiway C DG (mg/L) & $\leq 22.50$ & $(22.50,243.75]$ & $>243.75$ & $>22.50$ \\
Median D0 (mg/L) & 7.88 & 9.20 & 3.36 & 10.96 \\
\# Observations & 40 & 23 & 7 & 30 \\
\hline
\end{tabular}

Table 7 Groupings of DO observations in hold pad SW for the separated deicing and anti-icing glycol decision tree model.

\begin{tabular}{lccccc}
\hline \multicolumn{1}{c}{ Group } & 1 & 2 & 3 & 4 & 5 \\
\hline Site & & IN & IN & OF19 & OF19 \\
SW DG Lag (mg/L) & & $\leq 10582$ & $>10582$ & & \\
EW (mi/h) & $\leq-4.32$ & $>-4.32$ & $>-4.32$ & $>-4.32$ & $>-4.32$ \\
NS (mi/h) & & & & $\leq 1.67$ & $>1.67$ \\
Median D0 (mg/L) & 11.83 & 8.26 & 3.36 & 11.13 & 8.24 \\
\# Observations & 4 & 19 & 2 & 14 & 7 \\
\hline
\end{tabular}

\section{Conclusions}

The purpose of this paper was to test the DFW claim that used deicing fluids are completely captured by the deicing fluid collection systems installed at various deicing pad locations, consequently leaving only spent aircraft anti-icing fluids to run off and mix with the surrounding creeks and rivers. In addition to a decision tree model having total glycol usage as a predictor, as previously described in Fan et al. (2011), two new decision tree models were constructed: one having only anti-icing glycol usage as a predictor instead of total glycol usage; and one having separated deicing glycol usage and anti-icing glycol usage as predictors instead of total glycol usage.

The results showed that anti-icing glycol cases were far fewer than the deicing glycol cases thereby limiting the capability to find good predictive models using only anti-icing glycol usage. Furthermore, the decision tree models that involved only anti-icing glycol usage were deemed extremely weak, as, for almost all of the deicing pad locations, anti-icing glycol usage or anti-icing glycol usage lagged by a day did not show up as important variables. When separated deicing glycol usage and anti-icing glycol usage were included in the decision tree models, both appeared as important variables for several deicing pad locations and seemed to be at least as important as the total glycol usage variable in the decision tree model using total glycol usage as a predictor.

In addition, the analyses indicated that deicing glycol usage tended to be more important than anti-icing glycol usage for predicting DO concentrations in the airport receiving waters, contrary to the DFW claim of complete capture of deicing fluids by its deicing fluid collection systems set up at various deicing pad locations. Therefore, it would be practical to use a predictive model that includes separate deicing glycol usage and anti-icing glycol usage as predictors instead of total glycol usage.

\section{Acknowledgments}

We are grateful to Mr. Richard Reeter at Dallas Fort Worth International Airport for his useful comments. This study was supported by grants from Dallas Fort Worth International Airport.

\section{References}

Breiman, L., J. H. Friedman, C. J. Stone and R. A. Olshen. 1984. Classification and Regression Trees. Belmont, CA: Chapman \& Hall.

Bruno, G., E. Esposito and A. Genovese. 2015. "A Model for Aircraft Evaluation to Support Strategic Decisions." Expert Systems with Applications 42:5580-90.

Commercial and Business Aviation Training Manual. 2004. When in Doubt...: Small and Large Aircraft_-Aircraft Critical Surface Contamination Training for Aircrew and Groundcrew, 7th ed. Ottawa: Transport Canada. Report Number TP10643E. 
http://www.tc.gc.ca/publications/en/tp10643/pdf/hr/ tp10643e.pdf

Corsi, S. R., G. R. Harwell, S. W. Geis and D. Bergman. 2006. "Impacts of Aircraft Deicer and Anti-Icer Runoff on Receiving Waters from Dallas Fort Worth International Airport, Texas, USA." Environmental Toxicology and Chemistry 25:2890-900.

FAA Maintenance Handbook Series. 2012. Aviation Maintenance Technician Handbook-Airframe Volume 2. Oklahoma City, OK: U.S. Department of Transportation, Federal Aviation Administration, Airman Testing Standards Branch. FAA-H-8083-31.

FAA Report. 1996. Report on FAA Deicing Program at LaGuardia and O'Hare Airports. Washington, DC: U.S. Department of Transportation, Office of Inspector General. Report Number E5-FA-7-002. https://rosap.ntl.bts.gov/view/dot/12993

Fan, H., P. K. Tarun, V. C. P. Chen, D. T. Shih, J. M. Rosenberger, S. B. Kim and R. A. Horton. 2017. "Data-driven Optimization for Dallas Fort Worth International Airport Deicing Activities." Annals of Operations Research https://doi.org/10.1007/s10479-017-2747-1

Fan, H., P. K. Tarun, D. T. Shih, S. B. Kim, V. C. P. Chen, J. M. Rosenberger and D. Bergman. 2011. “Data Mining Modeling on the Environmental Impact of Airport Deicing Activities." Expert Systems with Applications 38:14899-906.

Hand, D., H. Mannila and P. Smyth. 2001. Principles of Data Mining. Cambridge, MA: MIT Press.

Hastie, T., R. Tibshirani and J. Friedman. 2009. The Elements of Statistical Learning-Data Mining, Inference, and Prediction. New York: Springer-Verlag.

Huo, X., S. B. Kim, K. L. Tsui and S. Wang. 2006. “FBP: A Frontier-Based Tree-Pruning Algorithm." INFORMS Journal on Computing 18 (4): 494-505. https://doi.org/10.1287/ijoc.1050.0133

Kim, S. B., J. M. Rosenberger, V. C. P. Chen, H. Fan and D. T. Shih. 2007. "Statistical Mining the Environmental Impact of Airport Deicing Activities." In IIE Annual Conference and Expo 2007: Industrial Engineering's Critical Role in a Flat World, Nashville, Tennessee-Conference Proceedings. Peachtree Corners, GA: Institute of Industrial and Systems Engineers.

Leist, D., K. Flowers, G. Bartley, B. Beebe, T. Giles and E. Ratcliff. 1997. Impacts of Deicing Fluids on Elijahs and Gunpowder Creeks, Boone County, Kentucky. Frankfort, KY: Kentucky Department for Environmental Protection, Division of Water. http://water.ky.gov/waterquality/Documents/ApprovedTMDL/ElijahsandGunpowderorganicenrichment.pdf
Mantas, C. J. and J. Abellán. 2014. “Credal-C4.5: Decision Tree Based On Imprecise Probabilities to Classify Noisy Data." Expert Systems with Applications 41:4625-37.

Masters, G. M. 1997. Introduction to Environmental Engineering and Science. Upper Saddle River, NJ: Prentice-Hall.

Mistikoglu, G., I. H. Gerek, E. Erdis, P. E. M. Usmen Mumtaz, H. Cakan and E. E. Kazan. 2015. “Decision Tree Analysis of Construction Fall Accidents Involving Roofers." Expert Systems with Applications 42:2256-63.

Narula, S. C. and J. F. Wellington. 1982. "The Minimum Sum of Absolute Errors Regression: A State of the Art Survey" International Statistical Review 50:317-26.

Revitt, D. M, and P. Worrall. 2003. “Low Temperature Biodegradation of Airport Deicing Fluids." Water Science and Technology 48:103-11.

Revitt, D. M., P. Worrall and D. Brewer. 2001. "The Integration of Constructed Wetlands into a Treatment System for Airport Runoff." Water Science and Technology 44: 469-76.

Switzenbaum, M. S., S. Veltman, T. Schoenberg, G. M. Durand, D. Mericas and B. Wagoner. 1999. Workshop: Best Management Practices for Airport Deicing Stormwater. Amherst, MA: University of Massachusetts, Amherst Water Resources Research Center. Publication No. 173. http://www.umass.edu/tei/wrrc/WRRC2004/pdf/Switz173. pdf

Torgo, L. 1999.Inductive Learning of Tree-Based Regression Models. Porto: University of Porto. PhD dissertation.

Tsui, K. L., V. C. P. Chen, W. Jiang and Y. A. Aslandogan. 2006. "Data Mining Methods and Applications." In Springer Handbook of Engineering Statistics, edited by H. Pham, 651-69. London: Springer-Verlag.

U.S. Environmental Protection Agency. 2000. Preliminary Data Summary: Airport Deicing Operations (Revised). Washington, DC: U.S. Environmental Protection Agency, Office of Water. EPA 821-R-00-016.

https://www.epa.gov/sites/production/files/2015-06/documents/airport-deicing-pds-2000.pdf 